\title{
The quality of life of Croatian women after mastectomy: a cross-sectional single-center study
}

Stana Pačarić ${ }^{1,2^{*}}$ D, Jozo Kristek ${ }^{1,2}$, Jure Mirat ${ }^{3}$, Goran Kondža ${ }^{1,2}$, Tajana Turk ${ }^{4,5}$, Nikolina Farčić ${ }^{2,6}$, Želimir Orkić ${ }^{1,2}$ and Ana Nemčić 1,2

\begin{abstract}
Background: Measuring the quality of life (QoL) of women with breast cancer is an important aspect of measuring treatment success. In Croatia, no QoL studies have been carried out with a focus on patients after mastectomy. The aim of this study was to examine QoL 1 month and 1 year after mastectomy.

Methods: This cross-sectional single-center study of quality of life was conducted in 101 patients, 50 of whom had undergone a mastectomy 1 month prior, and 51 of whom had undergone a mastectomy 1 year prior. The study was conducted from July 2015 to June 2016. The questionnaires used in the study were developed by the European Organisation for Research and Treatment of Cancer (EORTC). The questionnaire EORTC QLQ-C30 assesses the QoL of cancer patients, and the questionnaire EORTC QLQ-BR23 is a disease-specific breast cancer module. A chi square test, Fisher's exact test, Kolmogorov-Smirnov test, Student's t-test and Mann-Whitney U test were performed in the statistical analysis using the statistical program SPSS (Inc. Released 2008. SPSS Statistics for Windows, Version 17.0. Chicago: SPSS Inc.).

Results: Patients who had undergone a mastectomy a year earlier placed a higher value on their health state than did those who had undergone a mastectomy a month earlier. The most affected values of functional status on the EORTC QLQ-C30 scale were emotional functioning $(37.5$ [95\% Cl 33.3-61.6]) and sexual functioning (16.67 [95\% Cl 0-33.3]) 1 month and 1 year after mastectomy, respectively. The most affected symptoms on the EORTC QLQ-C30 scale were hair loss 66.67 [95\% Cl 33.3-100]) and fatigue 33.33 [95\% Cl 24-44]) 1 month and 1 year after mastectomy, respectively.

Conclusion: In our study, both functional and symptom scales were more affected in women 1 month after mastectomy. QoL was considerably improved in women 1 year after the surgery compared to 1 month after mastectomy. The results of this study could contribute to the public awareness of the QoL of breast cancer patients.
\end{abstract}

Keywords: Breast cancer, Quality of life, Mastectomy, Satisfaction, Woman

\footnotetext{
* Correspondence: stana.pacaric@gmail.com

${ }^{1}$ Department of Surgery, Faculty of Medicine, University of Osijek, Osijek,

Croatia

${ }^{2}$ Department of Surgery, University Hospital Osijek, Huttlerova 4, 31000

Osijek, Croatia

Full list of author information is available at the end of the article
}

(c) The Author(s). 2018 Open Access This article is distributed under the terms of the Creative Commons Attribution 4.0 International License (http://creativecommons.org/licenses/by/4.0/), which permits unrestricted use, distribution, and reproduction in any medium, provided you give appropriate credit to the original author(s) and the source, provide a link to the Creative Commons license, and indicate if changes were made. The Creative Commons Public Domain Dedication waiver (http://creativecommons.org/publicdomain/zero/1.0/) applies to the data made available in this article, unless otherwise stated. 


\section{Background}

Breast cancer is one of the most common malignant cancers, and it affects women all over the world [1]. In the Republic of Croatia, breast cancer is a significant public health problem and is the second leading cause of death after cardiovascular diseases. For the period between 2010 and 2014, the age-standardized incidence rate was 119.2 cases per 100,000 women, with a mortality rate of $48.3 \%$. There are 2644 (26\%) new cases every year [2]. In the world, as well as in Croatia, the number of cases of breast cancer has been increasing since the beginning of data collection on malignant diseases. For the period between 2009 and 2010, the data for Osijek-Baranya County are slightly higher than the Croatian average: 118 cases per 100.000 women per year [3]. The average life expectancy for women with breast cancer has risen significantly due to early diagnosis and new cancer treatments [4]. The average 5 -year survival rate is $85 \%$, whereas in developing countries, it is $50-60 \%$ [5]. Due to the increased survival of breast cancer patients, the impact of therapy on their quality of life (QoL) has become an important public health issue [6]. Although significant improvements have been made in recent decades regarding the detection and treatment of breast cancer, the disease still has a negative impact on social and physical functioning, especially in developing countries [7]. Only a study by Murgic et al. [8] has assessed the QoL in breast cancer patients in Croatia, comparing the QoL scores of patients receiving adjuvant treatment (adjuvant radiotherapy and adjuvant chemotherapy) with the QoL scores long-term breast cancer survivors.

Although no significant difference was found in QoL comparing these groups of patients, some scales of QoL were still more affected in long-term survivors, suggesting concomitant factors might contribute to overall QoL. No studies have been performed in Croatia with a focus primarily on patients after mastectomy. Quality-of-life measurements in women with breast cancer lately have become the focus of clinical practice and research, being significantly important in the assessment of treatment outcomes $[9,10]$. According to the World Health Organization (WHO), quality of life is defined as "the individual's perception of their position in life in the context of the culture and value systems in which they live and in relation to their goals" [11]. After mastectomy, women experience various functional and emotional disorders, such as depression, which leave serious psychosocial consequences. Some studies in western countries have shown that the prevalence of depression after mastectomy ranges from 1 to $56 \%$ [12]. Various treatments, such as surgical treatments, systemic therapy (chemotherapy, hormonal therapy, X-ray therapy and new targeted antibody therapy) and adjuvant endocrine therapy, affect the patient's quality of life [13].
Previous studies on quality of life, which assessed diagnosis, treatment, and healing, have shown that women with breast cancer are under increased risk of developing physical health problems (vomiting, sleep disorder and pain) and psychological distress (depression, anxiety, negative thoughts, fear of recurrence and death, feelings of being alone, sexual problems and poor self-image), all of which have a negative influence on quality of life and survival $[14,15]$.

\section{Objectives}

The aim of this study was to examine the quality of life of women with breast cancer after a month and after a year from surgery and to compare the quality of life after a month and after a year from mastectomy.

\section{Methods}

Study design and setting

A cross-sectional study of quality of life in two female groups with breast cancer - after a month and after a year from surgery (mastectomy) - was conducted during the period from July 2015 to June 2016. The study was conducted at the University Hospital Osijek, which is a tertiary care hospital in Osijek-Baranya County, Croatia, with population of 305,000 inhabitants. The research was approved by the Hospital Ethics Committee (reference number 25-1: 11425-3/2015).

\section{Study population}

The participants were enrolled during follow-up appointments at a thoracic surgery clinic.

The inclusion criteria were:

- women who had undergone a mastectomy (positive pathohistological finding of stage I or stage II breast cancer) 1 month earlier and were currently receiving adjuvant oncological therapy

The rationale for the chosen time point: patients have recovered from the surgery and are dealing with changes in QoL caused by the breast cancer diagnosis.

- women who had undergone a mastectomy (positive pathohistological finding of stage I or stage II breast cancer) 1 year earlier and were finished with adjuvant oncological therapy

Rationale for the chosen time point: patients have finished oncological therapy and are already accustomed to changes in QoL caused by the breast cancer diagnosis.

The exclusion criteria were age under 18 and/or over 75 , a life expectancy less than a year, cognitive and/or mental diseases, illiteracy, and an inability to communicate in the Croatian language. Patients who were included 
in the study 1 month after mastectomy were not included again 1year later. There were 108 patients who met the criteria. During the study, 5 patients withdrew their approval to participate, and 2 questionnaires were not correctly completed; thus, the number of participants was decreased to 101 (93.5\%). Before being asked to participate voluntarily, all participants were informed of the study's objectives and assured of anonymity. Upon giving informed consent, the participants were also informed of the confidentiality of personal data and given the anonymous questionnaire, which they completed and handed to the researcher. Filling out the questionnaire took approximately $20 \mathrm{~min}$.

\section{Study instruments}

The questionnaires used in the research were developed by the European Organisation for Research and Treatment of Cancer (EORTC), and they were approved, translated into Croatian and validated by EORTC Quality of Life Group [16].

The questionnaire EORTC QLQ-C30 (version 3) was developed to assess the quality of life of cancer patients and consists of 30 items including five functional scales: physical, role, cognitive, emotional and social functioning; three symptom scales: fatigue, pain and nausea/vomiting; scales of the global health status/quality of life; and six individual items or symptoms usually associated with malignant disease: dyspnea, appetite loss, insomnia, constipation, diarrhea and financial difficulties following disease treatment. The scales and items are evaluated on a Likert scale of 4 levels, ranging from 1 (not at all) to 4 (almost always). A higher number of points correlates to poorer functioning and more symptoms. The exception is the global health status/quality of life scale; this is evaluated on a 7-point linear analogue scale, where a higher score indicates greater satisfaction with the global health status and quality of life [17].

The questionnaire EORTC QLQ-BR23 is a disease-specific module for breast cancer. It consists of 23 items and four functional scales: body image functioning, sexual functioning, sexuality, future health function; and a symptom scale consisting of the side effects of treatment, breast and arm symptoms and hair loss. The scales and items are evaluated on a Likert scale of 4 levels, ranging from 1 (not at all) to 4 (almost always). A higher score indicates poorer functioning [17].

All the results in the Likert scales (scores 1-4) and the linear analogue scale (1-7) were transformed into scores from 0 to 100 according to EORTC scoring. A higher score on the functional scale correlates to a higher (better) functional level, while a higher score on the symptom scale represents a higher (worse) level of symptoms [17].

Sociodemographic data, which includes age, education, and marital status, as well as clinical variables such as chemotherapy were collected during interviews.

\section{Statistical methods}

To notice the effect of a 0.6 difference in numerical variables between the two independent participant groups, with a 0.05 difference in significance and a power of 0.8 , the minimum size needed for the statistical sample was 45 participants per group, i.e., the total sample size was 90 participants. (This calculation was made using G*Power software version 3.1.2, written by Franz Faul, University of Kiel, Germany).

Categorical data are presented in absolute and relative frequencies. Numerical data are described by median and limits of the interquartile range (IC). Differences of categorical variables were determined by a chi square test and, if necessary, by Fisher's exact test. The normality of the distribution of numerical variables was tested by the Kolmogorov-Smirnov test. Differences of numerical variables were tested by Student's t-test and variables that deviate from normal distribution by the Mann-Whitney $U$ test. All $P$ values are two-sided. The level of significance was set at alpha $=0.05$. The statistical program SPSS (Inc. Released 2008. SPSS Statistics for Windows, Version 17.0. Chicago: SPSS Inc.) was used for the statistical analysis.

\section{Results}

\section{Sociodemographic characteristics}

The study was conducted with 101 patients, 50 (49.5\%) of whom had undergone surgery 1 month earlier and 51 $(50.5 \%)$ of whom had undergone surgery 1 year earlier. The mean age of the patients was 56 years (standard deviation -8.3 years) in the one-month post-surgery group and 54 years (standard deviation - 8.3 years) in the one-year post-surgery group (Table 1). All the patients were white females.

Most of the patients $(n=49,48.5 \%)$ had completed secondary education and $66(65.3 \%)$ of them were married. Only 15 (14.9\%) patients were living alone, and 73 (72.3\%) of them considered the body image to be important and were familiar with the methods of reconstruction. There were $47(46.5 \%)$ patients would have reconstruction if recommended by their surgeon. Within the sample, 44 (44\%) patients started/underwent chemotherapy, 11 (11\%) patients underwent radiotherapy, $41(40 \%)$ patients had combined chemotherapy plus radiotherapy, and 5 (5\%) patients were receiving hormonal therapy (Table 2).

\section{Results for the EORTC QLQ-C30 questionnaire}

The median values of functional status were significantly higher in patients 1 year after mastectomy (80 [95\% CI 73.8-83.1]) compared to patients 1 month following mastectomy (57.78 [95\% CI 48.9-68.5]). The most affected values of functional status on the EORTC QLQ-C30 scale were emotional functioning (37.5 [95\% CI 33.3-61.6]) and sexual functioning (16.67 [95\% CI 0-33.3]) 1 month and 1 year after mastectomy, respectively. The symptom scale 
Table 1 The mean age of the patients and age upon the illness by groups

\begin{tabular}{|c|c|c|c|c|}
\hline & Arithmetic mean (stano & & & $p^{\mathrm{a}}$ \\
\hline & 1 month after surgery & 1 year after surgery & Total & \\
\hline Age of the patients & $56(7.6)$ & $55(8.9)$ & $56(8.3)$ & 0.660 \\
\hline Age at disease presentation & $55(7.6)$ & $54(8.8)$ & $54(8.3)$ & 0.291 \\
\hline
\end{tabular}

a Student's t-test

was more affected 1 month after mastectomy (38.46 [95\% CI 28.2-47.2]), compared to results 1 year following mastectomy (20.51 [95\% CI 15.3-28.2]) The symptoms on the EORTC QLQ-C30 scale most often affecting patients were hair loss 66.67 [95\% CI 33.3-100]) and fatigue 33.33 [95\% CI 24-44]) 1 month and 1 year after mastectomy, respectively. There were no significant differences in insomnia, constipation, diarrhea and financial difficulties between the groups. All the results are presented in Table 3.

\section{Results for the EORTC QLQ-BR23 questionnaire}

The QoL evaluated by the disease-specific scale QLQBR23 showed no significant differences between the two groups regarding body image functioning $(62,5$ $[95 \%$ CI $33,3-77,1]$ vs. 66,67 [95\% CI $66,6-83,1] 1$ month and 1 year after mastectomy, respectively) and anxiety over hair loss $(66,67$ [95\% CI 33,3-100] vs. 33,33 [95\% CI 11,1-33,3] 1 month and 1 year after mastectomy, respectively); these were the most affected items on the functional scale and the symptom scale, respectively. The functional scale in total was significantly more affected 1 year after the surgery (38.1 [95\% CI 20.8-58.3] vs. 54.17 [95\% CI 39.856.1]) 1 month and 1 year after mastectomy, respectively $(p=0.006)$ compared with the symptom scale 1 month after the surgery (36.75 [95\% CI 25.4-63.8] vs.

Table 2 The main features of the patients by groups

\begin{tabular}{|c|c|c|c|c|}
\hline & \multicolumn{3}{|l|}{ Number of patients (\%) } & \multirow[t]{2}{*}{$p^{a}$} \\
\hline & 1 month after surgery & 1 year after surgery & Total & \\
\hline \multicolumn{5}{|l|}{ Level of education } \\
\hline Unfinished primary school & $1(2)$ & $2(3.9)$ & $3(3)$ & \multirow[t]{5}{*}{0.331} \\
\hline Primary school & $15(30)$ & $7(13.7)$ & $22(21.8)$ & \\
\hline High school degree & $21(42)$ & $28(54.9)$ & $49(48.5)$ & \\
\hline College degree & $7(14)$ & $6(11.8)$ & $13(12.9)$ & \\
\hline University degree & $6(12)$ & $8(15.7)$ & $14(13.9)$ & \\
\hline \multicolumn{5}{|l|}{ Marital status } \\
\hline Single & $1(2)$ & $2(3.9)$ & $3(3)$ & \multirow[t]{5}{*}{0.428} \\
\hline Married & $33(66)$ & $33(64.7)$ & $66(65.3)$ & \\
\hline Common-law marriage & $3(6)$ & $2(3.9)$ & $5(5)$ & \\
\hline Divorced & $6(12)$ & $2(3.9)$ & $8(7.9)$ & \\
\hline Widowed & $7(14)$ & $12(23.5)$ & $19(18.8)$ & \\
\hline Live alone & $6(12)$ & $9(17.6)$ & $15(14.9)$ & $0.577^{\mathrm{b}}$ \\
\hline Body image is important to them & $35(70)$ & $38(74.5)$ & $73(72.3)$ & $0.661^{b}$ \\
\hline Familiar with the method of reconstruction & $32(64)$ & $41(80.4)$ & $73(72.3)$ & $0.078^{\mathrm{b}}$ \\
\hline Would agree to breast reconstruction if recommended by the surgeon & $25(50)$ & $22(43.1)$ & $47(46.5)$ & $0.552^{\mathrm{b}}$ \\
\hline \multicolumn{5}{|l|}{ Oncological therapy } \\
\hline Chemotherapy & $21(42)$ & $23(45)$ & $44(44)$ & \\
\hline Radiotherapy & $5(10)$ & $6(12)$ & $11(11)$ & \multirow[t]{3}{*}{0.96} \\
\hline Hormonal therapy & $3(6)$ & $2(4)$ & $5(5)$ & \\
\hline Chemotherapy + Radiotherapy & $21(42)$ & $20(39)$ & $41(40)$ & \\
\hline TOTAL & $50(100)$ & $51(100)$ & $101(100)$ & \\
\hline
\end{tabular}

${ }^{a} x^{2}$ test; ${ }^{b}$ Fisher's exact test 
Table 3 Median values of the scale QLQ-C30 by groups of patients and in relation to the time elapsed after the surgery

\begin{tabular}{|c|c|c|c|c|}
\hline \multirow{2}{*}{ QLQ-C30 } & \multicolumn{3}{|c|}{ Median (95\% Cl of median) } & \multirow[t]{2}{*}{$p^{*}$} \\
\hline & 1 month after surgery** & 1 year after surgery** & Total** & \\
\hline Global health status & $50(33.3-53.3)$ & $50(50-66)$ & $50(50-58)$ & 0.019 \\
\hline Physical functioning & $73.33(57.4-75.9)$ & 86.67 (80-93) & $80(73.3-86.7)$ & 0.003 \\
\hline Role functioning & $66.67(33.3-66.7)$ & $83.33(66.7-100)$ & $66.67(66-66.7)$ & 0.003 \\
\hline Emotional functioning & $37.5(33.3-61.6)$ & $66.67(58.3-74.7)$ & $58.33(43.1-66.7)$ & 0.014 \\
\hline Cognitive functioning & $75(66.7-83.3)$ & $83.33(83-100)$ & $83.33(83.3-83.3)$ & 0.045 \\
\hline Social functioning & $66.67(50-83)$ & $83.33(83-100)$ & $83.33(66.7-83.3)$ & 0.004 \\
\hline Functional scale total & $57.78(48.9-68.5)$ & $80(73.8-83.1)$ & $73.33(60.6-77.8)$ & 0.002 \\
\hline Fatigue & $55.56(40-67)$ & $33.33(22-44)$ & $44.44(33.3-55.6)$ & 0.039 \\
\hline Nausea/vomiting & $16.67(0-33)$ & $0(0-0)$ & $0(0-17)$ & 0.001 \\
\hline Pain & $41.67(29-54)$ & $16.67(16.7-17)$ & $16.67(16.6-33.3)$ & 0.014 \\
\hline Dyspnea & $33.33(33-67)$ & $33.33(0-33)$ & $33.33(33.3-33.3)$ & 0.007 \\
\hline Insomnia & $66.67(33-67)$ & $33.33(33-66.7)$ & $33.33(33.3-66.6)$ & 0.319 \\
\hline Appetite loss & $33.33(0-33)$ & $0(0-0)$ & $0(0-33.3)$ & 0.004 \\
\hline Constipation & $0(0-33)$ & $0(0-33.3)$ & $0(0-33.3)$ & 0.274 \\
\hline Diarrhea & $0(0-28)$ & $0(0-0)$ & $0(0-0)$ & 0.497 \\
\hline Financial difficulties & $33.33(33.3-66.7)$ & $33.33(0-33)$ & $33.33(0-33.3)$ & 0.139 \\
\hline Symptom scale total & $38.46(28.2-47.2)$ & $20.51(15.3-28.2)$ & $28.21(20.5-30.8)$ & 0.007 \\
\hline
\end{tabular}

*Mann-Whitney $\mathrm{U}$ test

**Higher score on the functional scale correlates to a higher (better) functional level; min: 0, max: 100

Higher score on the symptom scale represents a higher (worse) level of symptoms; min: 0, max: 100

21.43 [95\% CI 17.8-35.6]) 1 month and 1 year after mastectomy, respectively, $p<0.001)$. All the results are presented in Table 4.

\section{Discussion}

The purpose of this study was to assess the QoL of Croatian breast cancer patients in order to obtain results that could be used to raise public awareness on this issue, as well as to plan and perform educational and interventional programs for more effective support. In this study, we used questionnaires that represent a standard for the evaluation of the QoL of breast cancer patients [16]. Although there is a certain overlap between the two questionnaires, the EORTC QLQ-C30 focuses on the general QoL of cancer patients, while the questionnaire EORTC QLQ-BR23 is a disease-specific module for breast cancer and, therefore, is more focused on the disease-specific factors that contribute to QoL.

Table 4 Median values for the scales of the QLQ-BR23 by groups of patients and in relation to the time elapsed after the surgery

\begin{tabular}{|c|c|c|c|c|c|c|}
\hline \multirow[t]{2}{*}{ QLQ-BR23 } & \multicolumn{5}{|c|}{ Median ( $95 \% \mathrm{Cl}$ of median) } & \multirow[t]{2}{*}{$p^{*}$} \\
\hline & $\mathrm{N}$ & 1 month after surgery ${ }^{* *}$ & N & 1 year after surgery** & Total** & \\
\hline Body image functioning & 50 & $62.5(33.3-77.1)$ & 51 & $66.67(66.6-83.1)$ & $66.67(58.3-72.7)$ & 0.106 \\
\hline Sexual functioning & 50 & $16.67(0-16.7)$ & 49 & $16.67(0-33.3)$ & $16.67(0-16.7)$ & 0.388 \\
\hline Sexual enjoyment & 34 & $0(0-33.3)$ & 29 & $33.33(0-33.3)$ & $33.33(8.3-33.3)$ & 0.008 \\
\hline Future health function & 49 & $0(0-100)$ & 51 & $33.33(0-100)$ & $33.33(33.3-33.3)$ & 0.003 \\
\hline Functional scale total & 50 & $38.1(20.8-58.3)$ & 51 & $54.17(39.8-56.1)$ & $50(37.5-54.2)$ & 0.006 \\
\hline Systemic therapy side effects & 50 & $38.1(23.8-47.6)$ & 51 & $19.05(14.3-26.4)$ & 23.81 (19.04-33.3) & 0.001 \\
\hline Breast symptoms & 50 & $33.33(25-50)$ & 51 & $16.67(16.7-25)$ & $25(16.7-33.3)$ & 0.008 \\
\hline Arm symptoms & 50 & $44.44(33.3-55.6)$ & 51 & $22.22(11.1-33.3)$ & $33.33(22.2-44.4)$ & 0.001 \\
\hline Hair loss & 26 & $66.67(33.3-100)$ & 22 & $33.33(11.1-33.3)$ & $66.67(33.3-66.7)$ & 0.057 \\
\hline Symptom scale total & 50 & 36.75 (25.4-63.8) & 51 & $21.43(17.8-35.6)$ & $26.67(27.1-44.0)$ & $<0.001$ \\
\hline
\end{tabular}

*Mann-Whitney U test

**Higher score on the functional scale correlates to a higher (better) functional level; min: 0, max: 100

Higher score on the symptom scale represents a higher (worse) level of symptoms; min: 0, max: 100 
Functional scale for the EORTC QLQ-C30 questionnaire The patients scored their QoL on the EORTC QLQ-C30 functional scale high, regarding body, professional, cognitive and social functioning, regardless of the period analyzed. This indicated that the level of functioning was satisfactory. Nevertheless, according to our results, the patients valued their health state higher 1 year after mastectomy compared to patients who had their mastectomy a month previous. These results are similar to the Polish QoL study on patients within a year from mastectomy [18]. Most of the participants were not confined to bed and needed no help with daily activities, including dressing, bathing and eating. They were also able to continue with their free-time activities and had no problems with concentration or memory [19]. Reduced emotional functioning was noticed in all patients. Our results were similar to the results from other studies, i.e., the results indicated the presence of frustration, anger, depression or anxiety [19-21]. Physical appearance and body image were important, especially for younger women who lost their breast due to mastectomy. The depression that these women might experience could lead to reduced quality of life regarding social interactions, mental health, and emotional functioning [22, 23]. Emotional support was effective for women with breast cancer since it provided an opportunity to express their feelings and needs and to share their experience about the disease. It has been noted that, over time, women may perceive a decrease in emotional support, which may be related to personality factors or to one's psychological state [24]. Difficulties in emotional functioning influenced quality of life, especially during initial treatment when patients experienced the symptoms following adjuvant chemo-, radio- or hormonal therapy.

\section{Symptom scale for the EORTC QLQ-C30 questionnaire}

For those patients who had undergone surgery a month earlier, the most common symptoms on the EORTC QLQ-C30 scale were fatigue, nausea/vomiting, pain, dyspnea, and appetite loss. Fatigue was the most common, yet underestimated, side effect of cancer treatment for breast cancer patients. It is a disturbing, persistent and subjective feeling of physical, emotional and/or cognitive weakness related to cancerous disease. This symptom worsens during radiation therapy and even more during chemotherapy. Anemia was also a contributing factor of fatigue [25]. Different interventional strategies are needed in order to solve these problems, and interventions should be tailored to each patient's specific needs [26]. Chronic pain was the main clinical problem that affected 25 to $60 \%$ of patients. Developing chronic pain after breast cancer treatment, as well as after other surgical procedures, includes a complex pathophysiology consisting of pre-, intra- and postoperative factors [27]. The results showed that these painful symptoms could last for many years after mastectomy, thus decreasing the postoperative quality of life [28-31]. The results of a similar study conducted in Saudi Arabia that included 145 participants also showed disturbing symptoms such as insomnia, appetite loss and dyspnea [32].

\section{Symptom scale for the EORTC QLQ-BR23 questionnaire}

According to the results of the EORTC QLQ-BR23 questionnaire, patients who had a mastectomy a month previous were most affected by the side effects of systemic therapy, arm symptoms, breast symptoms and hair loss-associated discomfort. Previously, published studies had shown similar results $[20,21,33]$. In our study, all of these symptoms had significantly diminished 1 year after mastectomy, except for hair loss. Hair loss was often seen as a prominent side effect of chemotherapy. Alopecia has a negative impact on body image and psychosocial well-being, especially in women, and is a major cause of depression in breast cancer patients [34].

\section{Functional scale for the EORTC QLQ-BR23 questionnaire} According to our study, women value their overall functioning better a year after mastectomy compared to functioning a month after surgery. These results were noted in both general oncologic and disease-specific questionnaires. A month after surgery, patients expressed the most problems regarding sexual functioning and enjoyment, as well as concern regarding future health functioning. One year following the mastectomy, there was no significant improvement regarding sexual functioning. Sexual dysfunction might occur as a consequence of premature menopause after adjuvant endocrine therapy in breast cancer patients [35]. The results of the previous study [36] showed that breast cancer patients after mastectomy felt not only less attractive, but they also disliked their physical appearance and felt incomplete. This might cause patients to feel insecure and avoid social interactions. Women after mastectomy also experience more problems with sexual desire, arousal and orgasm, which leads to sexual disfunction [37, 38].

\section{Limitations}

The limitations of this study were its cross-sectional design as well as the small sample of participants.

There are also a variety of concomitant factors, an assessment of which was beyond the scope of this study, but that might influence the QoL of breast cancer patients, such as age, stage of disease at presentation, performance score of the patients, socioeconomic status, cultural values, spirituality, ethnicity, etc. [39-43]. Despite these limitations, the concept of disease-specific QoL questionnaires has been widely accepted and validated for their prognostic value in a clinical setting [44]. 


\section{Conclusion}

The study results showed that breast cancer has a significant negative impact on the quality of life of breast cancer patients. Both functional and symptom scales were more affected in women 1 month after mastectomy. The QoL was considerably improved in women 1 year after mastectomy compared to those at 1 month.

The results of this study could contribute to the public awareness of the QoL of breast cancer patients and could also be of use in planning and performing educational and interventional programs for more effective support. Due to the variety of problems these patients encounter, a multidisciplinary approach is warranted for successful improvement of the QoL of breast cancer patients.

\section{Abbreviations \\ EORTC QLQ-BR23 : European organization for research and treatment of cancer quality of life breast cancer questionnaire; EORTC QLQ-C30 (version 3): European organization for research and treatment of cancer quality questionnaire-cancer 30; EORTC: European organization for research and treatment of cancer; QoL: quality of life}

\section{Availability of data and materials}

The data sets used and/or analyzed during the current study are available from the corresponding author on reasonable request.

\section{Authors' contributions}

SP, JK and JM conceived the study and its original design. SP was the principal investigator. NF, TT and AN collected and analyzed the data. GK and $\mathrm{ZO}$ critically reviewed the manuscript. All authors read and approved the final manuscript.

\section{Ethics approval and consent to participate}

The research was approved by the University Hospital Osijek (reference number 25-1: 11425-3/2015). All participants were informed of the study's objectives and assurance of anonymity and have signed an informed consent form.

\section{Consent for publication}

Not applicable.

\section{Competing interests}

The authors declare that they have no competing interests.

\section{Publisher's Note}

Springer Nature remains neutral with regard to jurisdictional claims in published maps and institutional affiliations.

\footnotetext{
Author details

${ }^{1}$ Department of Surgery, Faculty of Medicine, University of Osijek, Osijek, Croatia. ${ }^{2}$ Department of Surgery, University Hospital Osijek, Huttlerova 4, 31000 Osijek, Croatia. ${ }^{3}$ Faculty of Medicine, University of Osijek, Cara Hadrijana 10/E, HR, 31000 Osijek, Croatia. ${ }^{4}$ Department of Biophysics and Radiology, Faculty of Medicine, University of Osijek, Osijek, Croatia. ${ }^{5}$ Department of Diagnostic and Interventional Radiology, University Hospita Osijek, Huttlerova 4, 31000 Osijek, Croatia. ${ }^{6}$ Department of Nursing, Medical Ethics and Palliative Medicine, Faculty of Medicine, University of Osijek, Osijek, Croatia.
}

Received: 27 January 2018 Accepted: 2 August 2018

Published online: 10 August 2018

\section{References}

1. Fann JR, Thomas-Rich AM, Katon WJ, Cowley D, Pepping M, McGregor BA et al. Major depression after breast cancer: a review of epidemiology and treatment. Gen Hosp Psychiatry. 2008;30:112-26.

2. Croatian Institute of Public Health. Croatian National Cancer Registry. Cancer Incidence in Croatia 2014. 2016. https://www.hzjz.hr/wp-content/uploads/ 2013/11/Bilten-2014_final.pdf. Accessed 16 Sept 2017.

3. Croatian Institute of Public Health. Croatian National Cancer Registry. Cancer Incidence in Croatia 2013. 2015. https://www.hzjz.hr/wp-content/uploads/ 2013/11/Bilten-2013_final.pdf. Accessed 16 Sept 2017.

4. Cangussu RDO, Soares TBDC, Barra ADA, Nicolato R. Sintomas depressivos no cancer de mama: Inventario de Depressao de Beck - Short Form. J Bras Psiquiatr. 2010;59:106-10.

5. Peter B, Levin B. WHO-IARC-World Health Organization International Agency for Research on Cancer (2008). In: Breast Cancer. Lyon: World Cancer Report; 2008.

6. Xiao C, Miller AH, Felger J, Mister D, Liu T, Torres MA. A prospective study of quality of life in breast cancer patients undergoing radiation therapy. Adv Radiat Oncol. 2016;1:10-6.

7. Anderson BO, Illbawi AM, El Saghir NS. Breast Cancer in low and middle income countries (LMICs): a shifting tide in Global Health. Breast J. 2015;21:111-8.

8. Murgić J, Soldić Ž, Vrljić D, Samija I, Kirac I, Bolanca A, Kusić Z. Quality of life of Croatian breast cancer patients receiving adjuvant treatment--comparison to long-term breast cancer survivors. Coll Antropol. 2012;36:1335-41.

9. Perry S, Kowalski TL, Chang C-H. Quality of life assessment in women with breast cancer: benefits, acceptability and utilization. Health Qual Life Outcomes. 2007;5:24.

10. Paraskevi T. Quality of life outcomes in patients with breast cancer. Oncol Rev. 2012;6:7-10.

11. THE WHOQOL GROUP. Development of the World Health Organization WHOQOL-BREF quality of life assessment. The WHOQOL Group. Psycho Med. 1998;28:551-8.

12. Zainal NZ, Nik-Jaafar NR, Baharudin A, Sabki ZA, Ng CG. Prevalence of depression in breast Cancer survivors: a systematic review of observational studies. Asian Pacific J Cancer Prev. 2013;14:2649-56.

13. Montazeri A. Health-related quality of life in breast cancer patients: a bibliographic review of the literature from 1974 to 2007. J Exp Clin Cancer Res. 2008;27:32.

14. Saleha SB, Shakeel A, Shumaila E, Shazia R, Rashid R, Ibrahim M. An assessment of quality of life in breast Cancer patients using EORTC QLQ C30/+Br23 questionnaire. Iran J Cancer Prev. 2012;3:98-104.

15. Montazeri A, Vahdaninia M, Harirchi I, Ebrahimi M, Khaleghi F, Jarvandi S Quality of life in patients with breast cancer before and after diagnosis: an eighteen months follow-up study. BMC Cancer. 2008:8:330.

16. Velikova G, Coens C, Efficace F, Greimel E, Groenvold M, Johnson C, Singer $\mathrm{S}$, et al. Health-related quality of life in EORTC clinical trials - 30 years of progress from methodological developments to making a real impact on oncology practice. EJC. 2012;10(Suppl 1):141-9.

17. Fayers P, Aaronson N, Bjordal K, Groenvold M, Curran D, Bottomley A. The EORTC QLQ-C30 Scoring Manual. 3rd edition. Brussels; 2001. http://www.eortc.be/qol/files/scmanualqlq-c30.pdf.

18. Kulesza-Bronczyk B, Dobrzycka B, Piekut K, Terlikowski R, MackowiakMatejczyk B, Wojno A, Terlikowski SJ. Quality of life during the first year after breast cancer resection. Progr Health Sci. 2014;4:124-9.

19. Lôbo SA, Carvalho Fernandes AF, De Almeida PC, De Lima Carvalho CM, Sawada NO. Quality of life in women with breast cancer undergoing chemotherapy. ACTA Paul Enferm. 2014;27:554-9.

20. Ganz PA, Kwan L, Stanton AL, Krupnick JL, Rowland JH, Meyerowitz BE, et al. Quality of life at the end of primary treatment of breast Cancer: first results from the moving beyond Cancer randomized trial. JNCI J Natl Cancer Inst. 2004;96:376-87.

21. Waldmann A, Pritzkuleit R, Raspe H, Katalinic A. The OVIS study: health related quality of life measured by the EORTC QLQ-C30 and-BR23 in German female patients with breast cancer from Schleswig-Holstein. Qual Life Res. 2007;16:767-76.

22. Bardwell WA, Fiorentino L. Risk factors for depression in breast cancer survivors : an update., Int J Clin. Health Psychol. 2012;12:311-31. 
23. Bardwell WA, Natarajan L, Dimsdale JE, Rock CL, Mortimer JE, Hollenbach K, et al. Objective cancer-related variables are not associated with depressive symptoms in women treated for early-stage breast cancer. J Clin Oncol. 2006:24:2420-7.

24. Fernandes AF, Cruz A, Moreira C, Santos MC, Silva T, Fernandes AF. Social support provided to women undergoing breast Cancer treatment: a study review. Adv Breast Cancer Res. 2014;3:47-53.

25. Manir KS, Bhadra K, Kumar G, Manna A, Patra NB, Sarkar SK. Fatigue in breast cancer patients on adjuvant treatment: course and prevalence. Indian J Palliat Care. 2012;18:109-16.

26. Bower JE, Bak K, Berger A, Breitbart W, Escalante CP, Ganz PA, et al. Screening, assessment, and management of fatigue in adult survivors of cancer: an American Society of Clinical Oncology clinical practice guideline adaptation. J Clin Oncol. 2014;32:1840-50.

27. Andersen KG, Kehlet H. Persistent pain after breast cancer treatment: a critical review of risk factors and strategies for prevention. J Pain. 2011;12:725-46.

28. Mejdahl MK, Andersen KG, Gartner R, Kroman N, Kehlet H. Persistent pain and sensory disturbances after treatment for breast cancer: six year nationwide follow-up study. BMJ. 2013;346:11865.

29. Gärtner R, Jensen M-B, Ewertz M, Kroman N, Kehlet H. Prevalence of and factors associated with persistent pain following breast cancer surgery. JAMA. 2009;302:1985-92.

30. Macdonald L, Bruce J, Scott NW, Smith WCS, Chambers WA. Long-term follow-up of breast cancer survivors with post-mastectomy pain syndrome. Br J Cancer. 2005;149:225-30.

31. Peuckmann V, Ekholm O, Rasmussen NK, Groenvold M, Christiansen P, Møller S, et al. Chronic pain and other sequelae in long-term breast cancer survivors: Nationwide survey in Denmark. Eur J Pain. 2009;13:478-85.

32. Almutairi KM, Mansour EA, Vinluan JM. A cross-sectional assessment of quality of life of breast cancer patients in Saudi Arabia. Public Health. 2016;136:117-25.

33. Gokgoz S, Sadikoglu G, Paksoy E, Guneytepe U, Ozcakir A, Bayram N, et al. Health related quality of life among breast Cancer patients: a study from Turkey. Glob J Health Sci. 2011;3:140-52.

34. Choi EK, Kim I-R, Chang O, Kang D, Nam S-J, Lee JE, et al. Impact of chemotherapyinduced alopecia distress on body image, psychosocial well-being, and depression in breast cancer patients. Psychooncology. 2014;23:1103-10.

35. Grimison PS, Stockler MR. Quality of life and adjuvant systemic therapy for early-stage breast cancer. Expert Rev Anticancer Ther. 2007:7:1123-34.

36. Engel J, Kerr J, Schlesinger-Raab A, Sauer H, Holzel D. Quality of life following breast-conserving therapy or mastectomy: results of a 5-year prospective study. Breast J. 2004;10:223-31.

37. McLaughlin SA, Cornell LF, Mussallem DM. Sexual function and breastspecific sensuality remain important after breast Cancer surgery. Ann Surg Oncol. 2017;24:3475.

38. Vaziri S, Lotfi KF. Sexuality after breast Cancer: need for guideline. Iran J Cancer Prev. 2012;5:10-5.

39. Levine EG, Yoo G, Aviv C. Predictors of quality of life among ethnically diverse breast cancer survivors. Appl Res Qual Life. 2017;12:1-16.

40. Samuel CA, Pinheiro LC, Reeder-Hayes KE, Walker JS, Corbie-Smith G, Fashaw SA, et al. To be young, black, and living with breast cancer: a systematic review of health-related quality of life in young black breast cancer survivors. Breast Cancer Res Treat. 2016;160:1-15.

41. Wen KY, Fang CY, Ma GX. Breast cancer experience and survivorship among Asian Americans: a systematic review. J Cancer Surviv. 2014;8:94-107.

42. Howard-Anderson J, Ganz PA, Bower JE, Stanton AL. Quality of life, fertility concerns, and behavioral health outcomes in younger breast cancer survivors: a systematic review. J Natl Cancer Inst. 2012;104:386-405.

43. Sammarco A, Konecny LM. Quality of life, social support, and uncertainty among Latina and Caucasian breast cancer survivors: a comparative study. Oncol Nurs Forum. 2010;37:93-9.

44. Nguyen J, Popovic M, Chow E, Cella D, Beaumont JL, Chu D, et al. EORTC QLQ-BR23 and FACT-B for the assessment of quality of life in patients with breast cancer: a literature review. J Comp Eff Res. 2015;4:157-66.

\section{Ready to submit your research? Choose BMC and benefit from:}

- fast, convenient online submission

- thorough peer review by experienced researchers in your field

- rapid publication on acceptance

- support for research data, including large and complex data types

- gold Open Access which fosters wider collaboration and increased citations

- maximum visibility for your research: over $100 \mathrm{M}$ website views per year

At BMC, research is always in progress.

Learn more biomedcentral.com/submissions 